\title{
Distrofia muscular de Duchenne associada à Pneumonia aspirativa: relato de caso e abordagem fisioterapêutica
}

\author{
Eduardo Matias dos Santos Steidl*; Vívian da Pieve Antunes*; \\ Cláudia Regina Beuter*
}

RESUMO: A Distrofia Muscular de Duchenne (DMD) é uma doença que gera alta incapacidade, devido sua rápida progressão e complicações associadas, principalmente as respiratórias. 0 artigo relata o caso de um adolescente de 19 anos portador de DMD, internado na UTI Pediátrica do Hospital de Caridade Astrogildo de Azevedo (HCAA), com diagnóstico de pneumonia aspirativa e insuficiência respiratória aguda, bem como a abordagem fisioterapêutica. A atuação da fisioterapia altera as perspectivas de qualidade e expectativa de vida, assim conhecer a doença favorece a elaboração de objetivos e intervenção de forma mais objetiva e eficiente. Nosso objetivo com este trabalho foi fornecer conhecimentos através de uma breve revisão bibliográfica sobre a doença e como a fisioterapia poderá conduzi-la no agravamento do quadro.

Descritores: Distrofia Muscular de Duchenne; Pneumonia Aspirativa; Fisioterapia.

\section{Duchenne Muscular Dystrophy associated by aspiratory pneumonia: case report and physiotherapeutic boarding}

ABSTRACT: The Duchenne Muscular Dystrophy (DMD) is an illness that generates high incapacity, due it's fast progression and complications associates, mainly the respiratory ones. The article tells the case of an adolescent of 19 years carrying of DMD, interned in the ICU Pediatric of the Hospital of Charity Astrogildo of Azevedo (HCAA), with diagnosis of aspiratory pneumonia and acute respiratory insufficiency, as well as the physiotherapeutic boarding. The performance of the physiotherapy modifies the quality perspectives and life expectancy, thus to know the illness favors the elaboration of objectives and intervention of more objective and efficient form. Our objective with this work was to supply knowledge through one brief bibliographical revision on the illness and as the physiotherapy will be able conduziz it knot aggravation of the picture.

Key-words: Duchenne Muscular Dysthrophy; Aspiratory pneumonia; Physiotherapy.

\footnotetext{
*Acadêmico do curso de Fisioterapia (UNIFRA), Santa Maria, RS, Brasil.

** Docente do curso de Fisioterapia (UNIFRA), Especialista em Fisioterapia Neurofuncional (IPARS), Santa Maria, RS, Brasil.

*** Docente do curso de Fisioterapia (UNIFRA), Mestre em Distúrbios da Comunicação Humana (UFSM), Santa Maria, RS, Brasil.
} 


\section{Introdução}

As miopatias hereditárias fazem parte de um grupo de patologias associadas pela degeneração progressiva e irreversível da musculatura esquelética e com diferentes padrões de herança. Dentre estas miopatias, as distrofias musculares tem sido objeto de muita pesquisa ${ }^{1}$, incluindo a Distrofia Muscular de Duchenne (DMD)².

A DMD, ou também conhecida como Distrofia Muscular Pseudo-hipertrófica, foi descrita pela primeira vez em 1868, pelo neurologista francês Guillaume Benjamin Duchenne, desde então a doença recebeu o nome em sua homenagem ${ }^{3}$. A doença é caracterizada por uma rápida progressão e é a mais grave de todas as distrofias musculares. Tendo sua etiologia hereditária, está ligada diretamente ao cromossomo $\mathrm{X}$ e é classificada como uma expressão fenotípica variável de um defeito genético no local Xp21, sendo que o produto deste gene anormal é um conteúdo muscular reduzido da proteína estrutural distrofina ${ }^{4}$.

Em decorrência de suas complicações, a perda da força muscular respiratória, leva ao declínio da função pulmonar, acarretando hipercapnia, podendo evoluir para insuficiência respiratória e tornando os pacientes vulneráveis a processos de atelectasias, pneumonias e retenção de secreções ${ }^{5,6}$.

De acordo com essas premissas, o presente artigo tem por objetivo relatar a abordagem fisioterapêutica na DMD associada à pneumonia aspirativa.

\section{Metodologia}

Relato de caso exploratório-descritivo, retrospectivo, de abordagem qualitativa. Foi realizado um levantamento documental, onde previamente foi assinado termo de consentimento livre e esclarecido pela responsável, através do prontuário eletrônico e exame físico do paciente e, na seqüência, foram elencadas as intervenções de fisioterapia mais adequadas para 0 restabelecimento funcional por meio da literatura. $\mathrm{O}$ projeto foi aprovado pelo Comitê de Ética do Hospital HCAA.

Para a coleta de dados, todos os dias foram anotados e verificados os objetivos e condutas aplicadas no paciente, a fim de registrar e monitorar a evolução clínica. A análise dos dados foi realizada pós-alta hospitalar do paciente por meio da equipe de fisioterapia pediátrica do hospital.

\section{Relato de caso e discussão do caso}

P.R.V., sexo masculino, 19 anos, trinta quilos na data da internação. Até os três anos teve seu desenvolvimento neuropsicomotor normal, atingindo fase de deambulação e independência em suas AVD's, sem a presença de comorbidades e história de internações pregressas. Aos quatro anos foi diagnosticado com Distrofia Muscular de Duchenne, pois começou apresentar dificuldade para levantar da posição deitada para em pé e histórico de quedas freqüentes.

ISSN 2236-5834 atraso no desenvolvimento neuropsicomotor após o terceiro ano de vida, associado com quedas freqüentes e dificuldades para correr e subir escadas. Outro sinal importante é a dificuldade de se levantar do chão (Sinal de Gowers) ${ }^{7}$, devido a uma fraqueza da musculatura extensora. 
Após apresentar intenso desconforto respiratório é internado na Unidade de Terapia Intensiva Pediátrica, do Hospital de Caridade Astrogildo de Azevedo (HCAA - Santa Maria, RS), em dez de julho de 2009, lúcido e responsivo (Glasgow 13). Foi diagnosticado com pneumonia aspirativa e insuficiência respiratória aguda, após Rx de tórax que apresentou zonas de hipotransparências em ápices com infiltrados peri-hilares e no exame gasométrico capilar $\mathrm{pH}=7,61 ; \mathrm{PCO}_{2}=21 \mathrm{mmHg} ; \mathrm{PO}_{2}=65 \mathrm{mmHg} ; \mathrm{HCO}_{3}=22$ e $\mathrm{BE}=+2$, onde houve necessidade de intubação orotraqueal e administração das seguintes medicações: Vancomicina, Altactone e Furosemida, e no dia seguinte foi submetido a cirurgia de gastrostomia e traqueostomia, permanecendo em ventilação mecânica invasiva modo controlado por dezoito dias e prescrição de fisioterapia respiratória e motora duas vezes ao dia.

Durante a avaliação fisioterapêutica foram econtradas deformidades torácicas acentuadas e fraqueza generalizada em todos os membros grau 1 conforme a Escala de Força Muscular de Kendall ${ }^{8}$. Tal achado corrobora a outros estudos realizados ${ }^{9,10}$, que demonstram que o desenvolvimento e o crescimento do tórax ocorrem de forma quase normal, sem ou com pouca perda da força muscular respiratória, e que devido a isso os volumes e capacidades pulmonares ficam preservados. Entretanto na fase onde a criança perde a capacidade de deambulação associada com uma escoliose de característica progressiva a capacidade vital tende a cair.

Bruin et al. ${ }^{11}$ afirmam que 0 fracasso ventilatório é a causa mais comum de mortalidade na DMD. A fraqueza da musculatura respiratória progressiva começa cedo, porém, devido à hipercapnia ser normalmente na fase pré-terminal, os autores sugerem ainda que o diafragma possa ser seletivamente poupado até uma fase tardia da doença, sendo comprometido somente quando ocorre a pseudo-hipertrofia de suas fibras.

Devido a essa fraqueza da musculatura respiratória e da hipercapnia, os pacientes portadores de DMD evoluem progressivamente para um estado de insuficiência respiratória ${ }^{5}$. Com o declínio progressivo da função pulmonar e com a associação da insuficiência respiratória, os pacientes se tornam vulneráveis a atelectasias, pneumonias aspirativas de repetição e retenção de secreções ${ }^{6}$.

Outro achado importante encontrado na criança foi a pseudo-hipertrofia da panturrilha. A falsa hipertrofia ocorre devido uma substituição das fibras musculares funcionais por tecido adiposo e conjuntivo acarretando a pseudo-hipertrofia (aumento do tecido conjuntivo entre as fibras) de certos grupos musculares, particularmente da panturrilha ${ }^{7}$.

A ausência de reflexos tendíneos, também foi um achado encontrado durante a avaliação física, indo de encontro com outros estudos ${ }^{7,13}$ que sugerem que devido à evolução da doença e a atrofia dos músculos, os reflexos tendíneos tornam-se deprimidos e, finalmente, perdemse, sem que ocorra perda sensorial, espasmos ou mialgias.

No segundo dia de internação foi coletada secreção traqueal com resultado negativo para pesquisa de fungos. No quarto dia foi feito tentativa com pressão suporte (PSV), onde 0 paciente apresentou fadiga, devido a isso se instalou a PSV por alguns momentos do dia e o restante mantendo-se em ventilação mecânica intermitente sincronizada (SIMV) até o décimo dia de internação.

A partir do décimo dia foi submetido a um protocolo de desmame em ventilação espontânea com Tubo $T$ por trinta minutos diários ${ }^{13}$, evoluindo da ventilação mecânica invasiva modo controlado para SIMV e no décimo oitavo dia para a ventilação por pressão positiva (BIPAP ${ }^{\circledR}$ ).

Saúde (Santa Maria), V.37, n.1, p. 09-16, 2011.

Stolz, A. B.; Miranda Jr., A. S. ; Foletto, E.; Praetzel, J.; Flores J. A. 
A ventilação por pressão positiva é um modo terapêutico que visa à reversão da hipercapnia e da insuficiência respiratória, podendo ser de modo invasivo ou não. Uma das escolhas para 0 tratamento por pressão positiva é o uso do BIPAP ${ }^{\circledR 14}$. Este aparelho é caracterizado pela inspiração ativa do paciente, gerando um fluxo de ar negativo, onde 0 sensor capta esse fluxo e transmite a pressão positiva de respiração para uma pressão limite pré-selecionada, ou seja, a respiração do paciente é sincronizada com a ventilação mecânica, podendo ser usada por meio de máscara nasal ou, em algumas circunstâncias, facial ${ }^{15}$.

Em pacientes como os portadores de DMD, devido à fraqueza severa da musculatura, a ventilação não-invasiva pode ser usada durante 0 dia e à noite, acoplado a cadeira de rodas do paciente utilizando uma bateria portátil como fonte de energia, permitindo ventilação mecânica quase contínua sem tubo ou traqueostomia ${ }^{16}$, prolongando a vida destes pacientes ${ }^{17}$.

Durante as sessões de fisioterapia, objetivou-se à prevenção do acúmulo e a eliminação de secreções das vias aéreas, melhora da ventilação e da resistência à fadiga, redução dos gastos energéticos durante a respiração, melhora das condições de expansão pulmonar favorecendo o trabalho diafragmático e, manutenção e melhora da mobilidade diafragmática6.

Dentre as principais técnicas de fisioterapia respiratória utilizadas, pode-se destacar:

- Vibratoterapia: consiste em vibrações manuais realizadas pelo fisioterapeuta com as mãos colocadas sobre 0 tórax do paciente, durante a fase expiratória ${ }^{18}$.

- Estímulo à tosse: técnica que visa à eliminação de secreções por meio de um estímulo dos receptores traqueais, realizando uma massagem na fúrcula esternal ${ }^{19}$.

- Estímulo diafragmático: técnica que auxilia na eficiência ventilatória, aumentando a excursão diafragmática e melhora a troca gasosa, além de facilitar o processo desobstrutivo ${ }^{20}$.

- Descompressão súbita: técnica considerada desobstrutiva e reexpansiva. 0 fisioterapeuta coloca as mãos abertas sobre o tórax do paciente com os polegares ao nível das últimas costelas. Deve-se acompanhar a expiração e, no final da mesma, é realizado um reflexo de estiramento sobre o tórax, favorecendo a expansão pulmonar $^{20}$.

- Alongamento dos músculos acessórios: o alongamento da musculatura acessória da inspiração, principalmente do esternocleidomastóideo, facilitam a ação do diafragma, evitando compensações que distorçam o tórax e, desta forma, prejudique a ventilação ${ }^{21}$.

Além da fisioterapia respiratória, a fisioterapia motora possui papel essencial no tratamento da doença. As anormalidades torácicas, como escoliose, são comuns em pacientes com DMD, como as que foram encontradas no paciente em questão, o que contribui para a expansão pulmonar reduzida devido à restrição da parede do tórax. Para amenizar a curvatura escoliótica, bem como encurtamentos, foram aplicadas técnicas de tração da coluna vertebral, pompage, mobilizações articulares e cinesioterapia. Silva ${ }^{22}$ e Amanajás ${ }^{23}$ salientam a importância de estimular a criança a realizar de forma lúdica exercícios livres, em várias posições, dentro de toda amplitude de movimento permitida, como para alcançar um objeto, com o objetivo de manter a flexibilidade geral, melhorar a coordenação, equilíbrio e prevenir encurtamentos musculares.

No vigésimo quarto dia de internação, o paciente recebeu alta hospitalar, com prescrição de fisioterapia domiciliar e suporte com ventilação mecânica não-invasiva. 


\section{Considerações Finais}

A DMD é uma doença altamente incapacitante, tanto física quanto social, devido suas complicações decorrentes da severa atrofia muscular, levando principalmente a complicações respiratórias. Frente a isso, a fisioterapia é de fundamental importância no seu tratamento, pois visa à manutenção da função pulmonar, bem como a prevenção destas complicações e a minimização das já instaladas, através de um arsenal de técnicas e recursos como a ventilação não-invasiva.

Ainda sugere-se a realização de estudos de ensaio clínico randomizados e controlados que visem demonstrar os reais resultados quanto à execução de treinamentos de força e resistência muscular respiratória durante tratamento fisioterapêutico em portadores de DMD.

\section{Referências}

1. Zatz M. A biologia molecular contribuindo para a compreensão e a prevenção das doenças hereditárias. Ciência \& Saúde Coletiva. 2002; 7(1): 85-89.

2. Reed UC. Doenças Neuromusculares. Jornal de Pediatria. 2002; 78(Supl.1): S89-S103.

3. Shepherd RB. Fisioterapia em Pediatria. $3^{\mathrm{a}}$ ed. São Paulo: Santos Livraria Editora; 1998.

4. Fenichel GM. Neurologia Pediátrica: Sinais e Sintomas. $2^{\text {a }}$ ed. Porto Alegre: Artes Médicas; 1995.

5. Christie HÁ, Goldstein L. Insuficiência Respiratória e a Necessidade de Suporte Ventilatório. In: Egan DS. Fundamentos da Terapia Respiratória de Egan. $7^{\mathrm{a}}$ ed. São Paulo: Manole; 2000.

6. Birnkrant DJ. The Assessment and Management of the Respiratory Complications of Pediatric Neuromuscular Diseases. 2002; 41: 301-308.

7. Thompson N. et al. Distúrbios Musculares. In: STOKES, M. Neurologia para Fisioterapeutas. São Paulo: Premier; 2000.

8. Kendall FP, Mcreary EK, Provance PG. Músculos provas e funções. $4^{\circ}$ Ed. São Paulo: Manole; 1995.

9. Slutzky LC. Fisioterapia Respiratória nas Enfermidades Neuromusculares. Rio de Janeiro: Revinter, 1997.

10. Leitão RA. et al. Distrofias Musculares. In: Lianza, S. Medicina de Reabilitação. $3^{a}$ Ed. Rio de Janeiro: Guanabara Koogan; 2001.

11. Bruin PF. et al. Diaphragm thickness and inspiratory strength in patients with Duchenne muscular dystrophy. Thorax. 1997; 52: 472-475.

12. Berhman RE. et al. Tratado de Pediatria. 16ª ed. Rio de Janeiro: Guanabara Koogan; 2002.

13. Schettino G, Pastore L, Vasconcelos AL, Nery P, Conishi R. Unidade de Terapia Intensiva do Hospital Sírio-Libanês - Padronização de Desmame da Ventilação Mecânica. Hospital Sírio-Libanês. 2004; 1: 1-9.

14. Birnkrant DJ, Pope JF, Eiben RM. Management of the respiratory complications of neuromuscular diseases in the pediatric intensive care unit. J Child Neurol. 1999; 14: 897-905.

15. Birnkrant DJ, Pope JF, Eiben RM. Pediatric noninvasive nasal ventilation. J Child Neurol. 1997; 10: 231 236.

16. Bach JR, Alba AS, Saporito LR. Intermittent positive pressure ventilation via the mouth as an alternative to tracheostomy for 257 ventilator users. Chest. 1993; 103: 174-182.

aúde (Santa Maria), v.37, n.1, p. 17-22, 2011.

Steidl, E. M. S.; Antunes, V. P.; Beuter, C. R. 
17. Baydur A, Layne E, Aral H, Krishnareddy N, Topacio R, Frederick G. et al. Long term non- invasive ventilation in the community for patients with musculoskeletal disorders: 46 year experience and review. Thorax. 2000; 55(1): 4-11.

18. Soares PRDI. Fisioterapia Respiratória para o Paciente Pneumológico. In: Silva LCC. Condutas em Pneumologia. Rio de Janeiro: Revinter; 2001.

19. Costa D. Fisioterapia Respiratória Básica. São Paulo: Atheneu; 1999.

20. Barbosa S. Fisioterapia Respiratória - Encefalopatia Crônica da Infância. Rio de Janeiro: Revinter; 2002.

21. Azeredo CC. Fisioterapia Respiratória Moderna. São Paulo: Manole; 2002.

22. Silva JDM, Costa KS, Cruz MC. Distrofia muscular de Duchenne: um enfoque cinesioterapêutico. Lato \& Sensu. 2003; 4(1): 3-5.

23. Amanajás DC. Distrofia muscular. Fisio \& Terapia. 2003; 7(39): 11-14.

\section{Eduardo Matias dos Santos Steidl}

Endereço para correspondência - Rua André Marques, n 617, Bairro Centro, CEP: 97010-041, Santa Maria, Rio Grande do Sul, Brasil.

E-mail_edumatias2005@gmail.com

Recebido em 01 de abril de 2011.

Aceito em 06 de julho de 2011. 